\title{
1. François Quesnay: The Circular Flow of Income and Input-Output Analysis
}

\subsection{Introduction}

Economic theorizing dates back to the time of Aristotle, but it was François Quesnay (1694-1774) who first formulated a model describing a whole economy, with empirical relevance and clear-cut, radical policy implications for the French economy and society. In this chapter we use his model as an introduction to input-output (IO) tables and IO analysis, focusing on a classic translation of Quesnay's (1759) Tableau Économique into IO language by Barna (1975). From this perspective, Quesnay's model provides an IO matrix with two commodities, corn and manufactured goods, where the corn input into the production of corn (agriculture) and manufacturing (including trade) also includes the subsistence consumption of workers as a representation of their direct labor input (as if they were cattle).

In this relatively simple two-commodity framework, we characterize productive and profitable production structures, and provide the general definition of the concepts of productiveness and profitability for general $n$-sectoral IO tables interpreted as linear production technologiesthat is, IO matrices with constant returns to scale in each sector. We show the equivalence of these two concepts and consider some related notions, such as Leontief-inverses and the multiplier analysis that is based on them, which together illustrate the dual structure (concerning quantities and prices) of IO analysis.

We then consider issues of decomposability for such IO models, leading to the Sraffian distinction between basic and nonbasic commodities and the analysis of non-cyclical technology structures. In the two-sectoral case considered by Quesnay we provide a complete taxonomy for these concepts, starting from Adam Smith's "early and rude state of society" (no physical inputs) and ending with a strictly 
positive IO matrix (such as the standard highly aggregated empirical IO tables).

We close the chapter with an application of the IO approach to the actual data of the German economy (1991-2000). We also briefly consider the United Nations' System of National Accounts (SNA) which will be important as a modeling framework in the following chapters. Consistent with the general approach adopted in this book, the main purpose of this chapter is not a textual exegesis of the work of François Quesnay, but rather an introduction to IO analysis that focuses on Quesnay's early approach to the circular flows of income and on the monetary circuit from which these flows derive. Blaug (1985) and Kurz and Salvadori (1995) provide further introductions to this important early example of macroeconomic theorizing.

\subsection{An early example of global economic reasoning}

The economy-wide model of an economic circuit which we will describe and discuss in this section, has been developed by François Quesnay, the personal physician of Madame de Pompadour at the court of King Louis XV in France. Quesnay was the leader of the Physiocrat school which stressed the role of nature as a source of wealth. In 1758, he presented his Tableau Économique to the king who showed no understanding of it or interest in it. This Tableau Économique applied the theory of the circulatory system in animals to an economy as a whole. Using this theoretical background, Quesnay wanted to contrast the desolate state of the French economy of his time with an ideal type of an economy with a healthy circulation of income.

In the Tableau Quesnay distinguishes two sectors of production: agriculture and manufacturing; and three social classes: property owners, entrepreneurs, and workers. For Quesnay, entrepreneurs and workers in the agriculture sector are part of the 'productive class', while those in the manufacturing sector constitute the 'sterile class'. Property owners consist of landlords, the king (including the court), and the church, where the latter two receive tax income and tithe payments out of the rent paid to landlords. In this scheme of circulation, landlords receive ground rent from agriculture, from which they transfer a certain amount to the king and church in the form of taxes. In broad strokes, the Tableau outlines how income circulates between the three classes in society, while also allowing an examination of the interaction of two sectors of production. Quesnay's Tableau also contains normative elements: it was meant in part as a proposal of economic reform addressed to the French ruling class. The 'state of 
bliss' presented in the Tableau represents the French economy operating at its optimal state of economic activity, in contrast to its actual state in the middle of the 18th century. The zig-zagging patterns depicting the interconnections between sectors and actors in the Tableau has been replaced by modern diagrams of the circular flow of goods and income in introductory economics texts, but the Tableau remains an informative starting point for introducing the logic of IO analysis.

Quesnay's model and physiocratic theory in general attemptedincluding 30 maxims or comparative static exercises - to provide the description of an optimal steady-state for an economy at the macro level. He provided an original, albeit crude image of a whole economy, by structuring it appropriately in its interdependencies in order to determine its stationary equilibrium in which the economy reproduces itself. However, the presentation of Quesnay's Tableau can be improved and made more general and flexible, if the monetary circuit of the economy in a particular year is represented by means of an IO accounting table. ${ }^{1}$

The first two columns of the IO Table 1.1 show the two sectors of Quesnay's Tableau: agriculture (total output 2625) and manufacturing (total output 1313). The middle three columns show the three actors of the Tableau, or types of households, while the next two columns show the government and church as the constituent parts of the state. Note that according to Quesnay only landlords have to pay taxes and tithe: 300 and 150, respectively. This represents an income transfer between households that is shown in the lower right-hand side of Table 1.1. The axiom of a closed circuit implies that column totals must equal row totals. Finally, social product net of intermediate inputs is $2625+1313-525-525=2888^{2}$

Table 1.1 shows that an IO representation of the whole economy (whether actual or idealized) is of great help for analyzing the transactions between the sectors in a given period. ${ }^{3}$ Along these lines, Table 1.1 serves as a starting point for both macro- and microeconomic analysis. As a foundation of macroeconomic analysis we can for example derive from Table 1.1 the following aggregated table for the French economy seen in Table 1.2.

The magnitudes in Table 1.1 are nominal and in order to move to

${ }^{1}$ As suggested by Barna (1975) in a pioneering contribution.

${ }^{2}$ Looking at individual sectors, it is important to note that in modern terminology, 'manufacturing' exhibits a positive value added, i.e., it is not unproductive or sterile as Quesnay claimed it to be.

${ }^{3}$ Of course, IO tables are nowadays structured differently, see United Nations (1993). 


\begin{tabular}{|c|c|c|c|c|c|c|c|c|}
\hline & \multicolumn{2}{|c|}{ Firms } & \multicolumn{3}{|c|}{ Households } & \multicolumn{2}{|c|}{ State } & \multirow[b]{2}{*}{ Total } \\
\hline & $\begin{array}{l}\text { Agric- } \\
\text { ulture }\end{array}$ & $\begin{array}{l}\text { Manu- } \\
\text { factur- } \\
\text { ing }\end{array}$ & $\begin{array}{l}\text { Far- } \\
\text { mer }\end{array}$ & $\begin{array}{l}\text { Manu- } \\
\text { factu- } \\
\text { rer }\end{array}$ & $\begin{array}{l}\text { Land- } \\
\text { lord }\end{array}$ & $\begin{array}{l}\text { Gover- } \\
\text { nment }\end{array}$ & $\begin{array}{l}\text { Chu- } \\
\text { rch }\end{array}$ & \\
\hline $\begin{array}{l}\text { Agric. } \\
\text { prod. }\end{array}$ & 525 & 525 & 525 & 525 & 300 & 150 & 75 & 2625 \\
\hline $\begin{array}{l}\text { Manf. } \\
\text { prod. }\end{array}$ & - & - & 525 & 263 & 300 & 150 & 75 & 1313 \\
\hline $\begin{array}{l}\text { Farm } \\
\text { inco- } \\
\text { me }\end{array}$ & 1050 & - & & & & & & 1050 \\
\hline $\begin{array}{l}\text { Manf. } \\
\text { inco- } \\
\text { me }\end{array}$ & - & 788 & & & & & & 788 \\
\hline Rent & 1050 & - & & & & & & 1050 \\
\hline Taxes & - & - & - & - & 300 & - & - & 300 \\
\hline Tithe & - & - & - & - & 150 & - & - & 150 \\
\hline Total & 2625 & 1313 & 1050 & 788 & 1050 & 300 & 150 & \\
\hline
\end{tabular}

Table 1.1: An IO representation of the Tableau Économique for a closed economy

\begin{tabular}{|c||c|c|c||c|}
\hline & Firms & Households & Government & Total \\
\hline \hline Consumption & 1050 & 2438 & 450 & 3938 \\
Gross Income & 2888 & - & - & 2888 \\
Taxes & - & 450 & - & 450 \\
(Government \& Church) & & & & \\
\hline \hline Total & 3938 & 2888 & 450 & \\
\hline
\end{tabular}

Table 1.2: An aggregation example as starting point for a macroeconomic analysis of the circuit of income

real magnitudes we assume that the prices of the two commodities in 
Quesnay's model are both equal to 1, i.e. we assume that the table has been deflated in a commodity specific way (using double-deflation rather than single-deflation techniques, see Chapter 7 below). Thus by assumption quantity and value are of the same size for all entries, except for values added, because there is no real magnitude behind them. In a two commodity world the physical table reads as in Table $1.3{ }^{4}$

\begin{tabular}{|c|c|c|c|c|c|c|c|c|}
\hline & \multicolumn{2}{|c|}{ Firms } & \multicolumn{3}{|c|}{ Households } & \multicolumn{2}{|c|}{ State } & \multirow[b]{2}{*}{ Total } \\
\hline & $\begin{array}{l}\text { Agric- } \\
\text { ulture }\end{array}$ & $\begin{array}{l}\text { Manu- } \\
\text { factur- } \\
\text { ing }\end{array}$ & $\begin{array}{l}\text { Far- } \\
\text { mer }\end{array}$ & $\begin{array}{c}\text { Manu- } \\
\text { factu- } \\
\text { rer }\end{array}$ & $\begin{array}{c}\text { Land- } \\
\text { lord }\end{array}$ & $\begin{array}{l}\text { Gover- } \\
\text { nment }\end{array}$ & $\begin{array}{c}\mathrm{Chu-} \\
\mathrm{rch}\end{array}$ & \\
\hline $\begin{array}{l}\text { Agric. } \\
\text { prod. }\end{array}$ & 525 & 525 & 525 & 525 & 300 & 150 & 75 & 2625 \\
\hline $\begin{array}{l}\text { Manf. } \\
\text { prod. }\end{array}$ & - & - & 525 & 263 & 300 & 150 & 75 & 1313 \\
\hline $\begin{array}{l}\text { Agric. } \\
\text { inco- } \\
\text { me }\end{array}$ & & & & & & & & \\
\hline $\begin{array}{l}\text { Manf. } \\
\text { inco- } \\
\text { me }\end{array}$ & & & & & & & & \\
\hline Rent & & & & & & & & \\
\hline \multicolumn{9}{|l|}{ Taxes } \\
\hline \multicolumn{9}{|l|}{ Tithe } \\
\hline Total & 2625 & 1313 & & & & & & \\
\hline
\end{tabular}

Table 1.3: The physical background of the Tableau Économique

This physical representation of the stationary circuit of a physiocrat world does not provide much microeconomic information. It shows neither how commodity prices are formed, nor how the allocation of quantities has been established, nor how the process of income distribution factors into the determination of price and quantity expressions. However, if we also assume the nominal rent payment of Quesnay's scheme (see Table 1.1), we can derive the actual profit

4 This table departs in some aspects from today's IO scheme as explained in Section 1.4 below. 
rates $r_{a}$ and $r_{m}$ in the two production sectors, with subscripts $a$ and $m$ respectively denoting agriculture and manufacturing. ${ }^{5}$ These two profit rates read:

$r_{a}=\frac{2625-525-1050}{525}=\frac{1050}{525}=2, \quad r_{m}=\frac{1313-525}{525}=\frac{788}{525}=1.5$.

The number 525 in the numerator and the denominator indicates that the agricultural product (and only this) has been used in both sectors as an intermediate input, therefore denoting the capital advanced and the reference against which profit rates are calculated. Both sectors are profitable with profit rates of 200 and 150 percent, respectively. Profits before rent payments in agriculture are higher than in manufacturing. This fits with Quesnay's theory that agriculture is responsible for generating all of the transfer payments in this economy, thus this sector must be highly productive. In the profit rate calculations it is assumed that workers' wages are contained in the intermediate inputs of firms - if wages are considered at all, they only guarantee subsistence (in terms of corn). The surpluses obtained in this framework are consistent with the Marxian notion of surplus, since they represent the excess product, or value created by workers.

In general, IO theory considers average IO coefficients and assumes constant returns to scale. This allows for the determination of actual physical inputs per unit of output. On this basis, we arrive at the following IO matrix, or technology $A=\left[a_{i j}\right]$ of physical intermediate inputs: ${ }^{6}$

\begin{tabular}{|l|c|c|}
\hline & agriculture & manufacturing \\
\hline agric. products & $a_{11}=\frac{525}{2525}=0.2$ & $a_{12}=\frac{525}{1313}=0.4$ \\
\hline manuf. products & $a_{21}=0$ & $a_{22}=0$ \\
\hline output & 1 & 1 \\
\hline
\end{tabular}

Table 1.4: The unit-output representation of the linear technology behind Quesnay's Tableau

So far we have assumed that both commodity prices are equal to 1 .

${ }^{5}$ Uniform profit rates resulting from ruthless competition will be analyzed in the next chapter.

${ }^{6}$ It is worth noting that the IO matrix $A$ and its elements $a_{i j}$ should include some notion of time $t$, i.e. $A_{t}$ or $a_{i j ; t}$. However, for simplicity, time subscripts will be dropped in the following presentation. 
These prices can be understood as administered prices since Quesnay wanted to support agriculture compared to 'trade', the 'sterile' sector of his model. As we have seen, under this assumption the profit rates in the two sectors are 200 and 150 percent. In order to show that a sector of the economy is truly sterile, the profit rate in trade would need to be zero. This occurs, if, rather than $p_{a}=p_{m}=1$, we have $p_{a}=1$ and $p_{m}=0.4$, thus $p_{m} \cdot 1313-p_{a} \cdot 525=0$. In this scenario manufacturing does not create a surplus and the physical IO scheme would have to be changed since the monetary magnitudes now imply different final demands.

Alternatively, in place of administered prices intended to support agriculture, one can also follow Quesnay and assume that competition is freed from regulations and assume that profit rates are equalized by capital flows across the two sectors. In the case of a linear technology and with rent payment fixed in nominal terms, the resulting profitand price-structure is: $p_{a}=1$ (and so $r_{a}=\left(1-a_{11}-2 / 5\right) / a_{11}=2$ ), $p_{m}=\left(1+r_{a}\right) a_{12}=1.2 .^{7}$

\subsection{Input-output analysis: Surplus, multipliers and connectedness}

The tables of Section 1.2 show that Quesnay's Tableau can be viewed as a precursor to modern IO economics. We now consider the standard IO framework that relies on a single table to represent the circuit between production, income, and demand. This type analysis was initiated by Wassily Leontief in the 1930s and grew to become the standard treatment for analyzing linear economies as IO systems, an approach which lays the foundation for the analysis conducted throughout the rest of the book.

Consider a closed economy with $n$ industries producing $n$ goods that are also used as intermediate inputs. Let $X_{i j}$ denote the physical amount of the commodity produced by sector $i$ transferred to sector $j$ and let $p_{i}$ denote the price of commodity $i$. Sector $i$ also sells its product as final demand (a final good) $y_{i}$, thus its total output is $x_{i}=\sum_{1}^{n} X_{i j}+$ $y_{i}$. In contrast to Quesnay's Tableau, for the sake of simplicity, we consider the annual production of $n$ industries, the distribution between them, and final demands in a single aggregated column in Table 1.5. The diagonal matrix formed from a price vector $p$ is denoted as $\hat{p}$. The value added by each sector $i$ is denoted by $\nu_{i}$, with $\nu$ denoting the vector of sectoral value added across the $n$ sectors.

${ }^{7}$ Competitive prices will, however, change demand again thereby changing output, an issue beyond our current consideration. 
The connections between industries in commodity production are represented in Table 1.5 in terms of quantities $X_{i j}$ as well as values $p_{i} X_{i j}$. Magnitudes without explicit reference to prices $p_{j}$ represent pure value magnitudes that cannot be meaningfully split into a single price and a single quantity component ('value added' being the difference between homogeneous sales and heterogenous costs). Note that in such a consistent ex post representation of the activities of a whole economy total value added $\sum_{i} \nu_{i}$ of the $n$ branches must be identical to the value of total final demand $\sum_{i} p_{i} y_{i}$, i.e. $\sum_{i} p_{i} y_{i} \equiv \sum_{i} \nu_{i}$. However, such an identity is not true for sectoral values added and their final demands.

\begin{tabular}{|l||c|c|c|c||c|}
\hline $\begin{array}{l}\text { Delivery from } \downarrow \\
\text { to } \rightarrow\end{array}$ & Sector 1 & $\ldots$ & Sector $n$ & $\begin{array}{c}\text { Final } \\
\text { demand }\end{array}$ & $\begin{array}{c}\text { Row sum } \\
\text { (Total } \\
\text { production) }\end{array}$ \\
\hline \hline Sector 1 & $p_{1} X_{11}$ & $\ldots$ & $p_{1} X_{1 n}$ & $p_{1} y_{1}$ & $p_{1} x_{1}$ \\
\hline Sector 2 & $p_{2} X_{21}$ & $\ldots$ & $p_{2} X_{2 n}$ & $p_{2} y_{2}$ & $p_{2} x_{2}$ \\
\hline$\ldots$ & $\ldots$ & $\ldots$ & $\ldots$ & $\ldots$ & $\ldots$ \\
\hline Sector $n$ & $p_{n} X_{n 1}$ & $\ldots$ & $p_{n} X_{n n}$ & $p_{n} y_{n}$ & $p_{n} x_{n}$ \\
\hline Value added & $\nu_{1}$ & $\ldots$ & $\nu_{n}$ & & \\
\hline $\begin{array}{l}\text { Column sum } \\
\text { (Total } \\
\text { production) }\end{array}$ & $p_{1} x_{1}$ & $\ldots$ & $p_{n} x_{n}$ & & $\sum_{i} p_{i} x_{i}$ \\
\hline
\end{tabular}

Table 1.5: The basic structure of a nominal IO table $\left(\hat{p}\left[X_{i j}\right]\right)$

If one divides the first $n$ columns of Table 1.5 by the total value of the corresponding output $p_{j} x_{j}$ one obtains the matrix, shown in Table 1.6, whose elements are all dimensionless. Letting the superscript nom represent nominal quantities, the matrix $A^{\text {nom }}$ represents the intermediate inputs of the different sectors per value of one unit of output and can be written as follows:

$$
A^{\text {nom }}=\left[a_{i j}^{n o m}\right]=\left[p_{i} X_{i j} / p_{j} x_{j}\right]=\left[p_{i} a_{i j} / p_{j}\right], \quad \text { with } \quad a_{i j}=X_{i j} / x_{j} .
$$

Table 1.6 does not provide a pure quantity representation of the economy, since quantities are still multiplied by the appropriate relative prices. If one removes relative prices from the IO table one finally obtains the physical data of Table 1.7 as a starting point for the IO analysis. The theoretical IO coefficients $a_{i j}=X_{i j} / x_{j}$ represent the 


\begin{tabular}{|l|c|l||c|}
\hline $\begin{array}{l}\text { Delivery from } \downarrow \\
\text { to } \rightarrow\end{array}$ & Sector 1 & $\ldots$ & Sector $n$ \\
\hline Sector 1 & $a_{11}^{\text {nom }}$ & $\ldots$ & $a_{1 n}^{\text {nom }}$ \\
\hline$\ldots$ & $\ldots$ & $\ldots$ & $\ldots$ \\
\hline Sector $n$ & $a_{n 1}^{\text {nom }}$ & $\ldots$ & $a_{n n}^{\text {nom }}$ \\
\hline Value added & $\nu_{1} /\left(p_{1} x_{1}\right)$ & $\ldots$ & $\nu_{n} /\left(p_{n} x_{n}\right)$ \\
\hline $\begin{array}{l}\text { Unit output } \\
\text { (value) }\end{array}$ & 1 & $\ldots$ & 1 \\
\hline
\end{tabular}

Table 1.6: The nominal unit coefficients of a linear technology behind Table 1.5: $A^{\text {nom }}=\hat{p} X \hat{x}^{-1} \hat{p}^{-1}$

amount of product $i$ per unit of product $j$ and therefore can no longer be added to each other, in contrast to the previous table (unlike in Table 1.6) where both row and column summation are possible. The average IO coefficients $a_{i j}$ (the average amount of good $i$ that is used up in the production of good $j$ ) are generally interpreted as representing a linear technology (fixed proportions in production and constant returns to scale) - this interpretation is retained throughout the book.

\begin{tabular}{|l|c|l|c|}
\hline $\begin{array}{l}\text { Delivery from } \\
\text { to } \rightarrow\end{array}$ & Sector 1 & $\ldots$ & Sector $n$ \\
\hline \hline Sector 1 & $a_{11}$ & $\ldots$ & $a_{1 n}$ \\
\hline$\ldots$ & $\ldots$ & $\ldots$ & $\ldots$ \\
\hline Sector $n$ & $a_{n 1}$ & $\ldots$ & $a_{n n}$ \\
\hline $\begin{array}{l}\text { Unit output } \\
\text { (quantity) }\end{array}$ & 1 & $\ldots$ & 1 \\
\hline
\end{tabular}

Table 1.7: The physical coefficients of a linear technology assumed behind the IO Table 1.5: $A=\hat{p}^{-1} A^{n o m} \hat{p}=X \hat{x}^{-1}, x=\left[x_{1}, \ldots, x_{n}\right]^{\prime}$, $p=\left[p_{1}, \ldots, p_{n}\right]$

\subsubsection{Productive and profitable input-output matrices}

The linear production structure given by the nonnegative $n \times n$ matrix $A \geq 0$ allows us to define the notions of 'productiveness' and 'profitability'. Unlike in Quesnay's model, we consider labor inputs $l \in \mathbb{R}^{n}$ (a row vector) explicitly rather than in the intermediate inputs 
via a given consumption basket $c \in \mathbb{R}^{n}$ (a column). Considering $l$ separately incorporates labor costs as part of the value added of each sector, therefore, a positive value added does not necessarily imply positive profits.

\section{Definition 1.1. ('Productive' and 'Profitable').}

(1) The matrix of intermediate inputs $A \in \mathbb{R}^{n \times n}$ is called productive, if there is a vector of activity levels $x \geq 0$ in $\mathbb{R}_{+}^{n}$ for the $n$ industries, such that $A x<x$ holds, i.e., for all rows $A_{i \star}$ of $A$, $A_{i \star} x=\sum_{j} a_{i j} x_{j}<x_{i}$ holds.

(2) The matrix of intermediate inputs $A \in \mathbb{R}^{n \times n}$ is called profitable, if there is a price vector $p \geq 0$ in $\mathbb{R}_{+}^{n}$ for the $n$ commodities, such that $p A<p$ holds, i.e., for all columns $A_{\star j}$ of $A, p A_{\star j}=\sum_{i} p_{i} a_{i j}<p_{j}$ holds.

Productive matrices are therefore characterized by the existence of a nonnegative vector of activity levels $x^{\prime}=\left(x_{1}, \ldots, x_{n}\right)$ of the $n$ industries of our model economy, such that the output $x_{i}$ of each industry $i$ (rows of $A$ ) is larger than the total consumption $A_{i \star} x$ of good $i$ by the $n$ industries. All sectors of the economy produce a positive surplus in this case. Similarly, an IO matrix is profitable, if there is a nonnegative vector of prices $p$, such that unit production costs (excluding labor costs) in each industry $j$ (columns of $A$ ) $p A_{\star j}$ are always lower than the price of the commodity $p_{j}$. The second criterion considers each sector in isolation (but with a common price structure for all sectors), while the first criterion compares the consumption and output for each commodity over the whole set of industries. We show below that a matrix $A$ is productive if and only if it is profitable - in a sense, both comparisons lead to the same set of nonnegative matrices which provide the basis for all later price-quantity considerations - the central subject of this book.

Let $M=I-A$, where $I$ is the $n$-dimensional identity matrix. Definition 1.1 still applies to $A$ via $M$ by $M x=y$, where $y$ represents the vector of final demands $\left(y^{\prime}=\left(y_{1}, \ldots, y_{n}\right)\right)$ and $p M=\nu>0$. Stated differently, these equation systems can be solved for at least one semipositive vector of final demands $y>0$ and at least one semi-positive vector of values added $\nu>0$ by means of gross output levels $x \geq 0$ or commodity prices $p \geq 0$. This is more formally stated by Proposition 1.1, which summarizes results of Nikaido (1968).

\section{Proposition 1.1.}

(1) The matrix of intermediate inputs $A$ is productive if and only if for all nonnegative vectors of final demands $y \in \mathbb{R}_{+}^{n}$ there is a 
nonnegative vector of activity levels $x \in \mathbb{R}_{+}^{n}$, which provides the surplus $y$, i.e., such that $M x=y$.

(2) The solution $x$ of the linear equation system $M x=y$ is given by:

$$
\begin{aligned}
x & =M^{-1} y=(I-A)^{-1} y=\left(I+A+A^{2}+A^{3}+\ldots\right) y \\
& =y+A y+A^{2} y+A^{3} y+\ldots,
\end{aligned}
$$

if and only if $A$ is productive. Because the matrix $I-A$ is then invertible $(I-A)^{-1}$, the so-called "Leontief-inverse", is nonnegative and representable by means of a standard multiplier formula (or geometric series that holds for all dimensions $n$ ).

(3) The matrix of intermediate inputs $A$ is profitable if and only if for all nonnegative vectors of value added $\nu \in \mathbb{R}_{+}^{n}$ there is a nonnegative vector of prices $p \in \mathbb{R}_{+}^{n}$ which generates value added $\nu=\left(\nu_{1}, \ldots, \nu_{n}\right)$ per unit of output of the $n$ industries, i.e., such that $p M=\nu$.

(4) The solution $p$ of this equation is then (and only then) given by the following expressions:

$$
\begin{aligned}
p & =\nu M^{-1}=\nu(I-A)^{-1}=\nu\left(I+A+A^{2}+A^{3}+\ldots\right) \\
& =\nu+\nu A+\nu A^{2}+\nu A^{3}+\ldots
\end{aligned}
$$

The matrix $M=I-A$ is then invertible and nonnegative.

In other words the possibility of surplus production in each branch of the economy implies that every semi-positive demand for the $n$ commodities of the $n$ sectors can be satisfied by choosing an appropriate uniquely determined vector of activity levels. Similarly, the economy can generate any semi-positive value added vector $\nu=\left(\nu_{1}, \ldots, \nu_{n}\right)$ by choosing an appropriate vector of commodity prices. Moreover, such activity and price levels needed are determined by applying the relevant Leontief multipliers. Finally, as shown in Proposition 1.2, any one of these conditions implies the validity of all others, for example one only needs to assume a productive IO structure in order to fulfill all other assertions on the flexibility of such an IO system, with completely rigid proportions in production.

Proposition 1.2. (Hawkins-Simon Conditions). Consider the IO matrix $A \geq 0$, and the corresponding difference matrix $M=I-A$. The following conditions are equivalent:

(1) The matrix of intermediate inputs $A$ is productive.

(2) The matrix $A$ is profitable. 
(3) The upper left-hand principal minors of $M$ are all positive. $\operatorname{det}\left(m_{i j}\right)>0, i=1, \ldots, k, j=1, \ldots, k,(k=1, \ldots, n)$.

(4) All principal minors of $M$ are positive: $\operatorname{det}\left(m_{i i}\right)>0, \quad i \in N, N \subset$ $\{1, \ldots, n\}$.

For low dimensional economies condition (3) of Proposition 1.2 provides an easily applicable routine, to check the productiveness and profitability of nonnegative IO matrices. For example, in the case $n=2$, it is sufficient to check that $m_{11}$ and $\operatorname{det} M$ are both positive and in the case $n=3$ we have to check in addition that $m_{11} m_{22}-m_{12} m_{21}>0$ holds true.

\subsubsection{1 'Productiveness' and 'profitability' in Quesnay's economy}

The notions of productiveness and profitability can be illustrated by means of a simple two-commodity example based on the IO matrix from Table 1.8, which is a more general version of the IO matrix in Table 1.4-effectively our earlier example of Quesnay's Tableau.

\begin{tabular}{|l|c|c|}
\hline & Agriculture & $\begin{array}{c}\text { Manu- } \\
\text { facturing }\end{array}$ \\
\hline \hline Agricultural products & $a_{11}$ & $a_{12}$ \\
\hline Manufacturing products & 0 & 0 \\
\hline \hline Total output & 1 & 1 \\
\hline
\end{tabular}

Table 1.8: A simple two-sector IO matrix

The IO matrix $A$, the difference matrix $M$, and the corresponding vectors of activity levels $x$ and prices $p$ of Table 1.8 can be written as

$$
\begin{gathered}
A=\left[\begin{array}{cc}
a_{11} & a_{12} \\
0 & 0
\end{array}\right], \quad M=\left[\begin{array}{cc}
1-a_{11} & -a_{12} \\
0 & 1
\end{array}\right], \\
x=\left[\begin{array}{l}
x_{1} \\
x_{2}
\end{array}\right], \quad p^{\prime}=\left[\begin{array}{l}
p_{1} \\
p_{2}
\end{array}\right] .
\end{gathered}
$$

The $A$ matrix is immediately shown to be productive as well as profitable, for example by means of the vectors $x^{\prime}=(1,1)$ and $p=(1,1)$, provided $a_{11}<1$, which ensures that the principal minors of $M$ are positive. As a result, the geometric series in Proposition 1.1 are well-defined and converge towards the Leontief-inverse. Thus, it is 
possible to calculate the vectors of activity levels and prices implied by given vectors of final demand or monetary surpluses. In detail, the matrix powers read as follows:

$$
\begin{gathered}
A^{2}=\left[\begin{array}{cc}
a_{11}^{2} & a_{12} a_{11} \\
0 & 0
\end{array}\right], \quad A^{3}=\left[\begin{array}{cc}
a_{11}^{3} & a_{12} a_{11}^{2} \\
0 & 0
\end{array}\right], \\
A^{4}=\left[\begin{array}{cc}
a_{11}^{4} & a_{12} a_{11}^{3} \\
0 & 0
\end{array}\right], \text { etc. }
\end{gathered}
$$

Carrying the procedure further and summing these matrices with the two-dimensional identity matrix $I$ :

$$
I+A+A^{2}+A^{3}+A^{4}+\ldots=\left[\begin{array}{cc}
1 /\left(1-a_{11}\right) & a_{12} /\left(1-a_{11}\right) \\
0 & 1
\end{array}\right]
$$

This result is an analog to macroeconomic multiplier analysis. Typically, in macroeconomics, multipliers are formulated in a onecommodity world and the expenditure multiplier is derived with reference to households' marginal propensity to consume, for given levels of investment and government expenditures in place of intermediate products. Similarly, the above result can be viewed as the sum of the indirect effects of autonomous changes in demand, thereby capturing the essence of the well-known multiplier effect in macroeconomics.

Testing the consistency of the above calculation, the vector of activity levels $x=\left(x_{1}, x_{2}\right)^{\prime}$ corresponding to the vector of final demands $y=\left(y_{1}, y_{2}\right)^{\prime}$ reads:

$$
x=\left[\begin{array}{cc}
1 /\left(1-a_{11}\right) & a_{12} /\left(1-a_{11}\right) \\
0 & 1
\end{array}\right] y=\frac{1}{1-a_{11}}\left[\begin{array}{c}
y_{1}+a_{12} y_{2} \\
\left(1-a_{11}\right) y_{2}
\end{array}\right]
$$

and thus

$$
A x=\frac{1}{1-a_{11}}\left[\begin{array}{c}
a_{11}\left(y_{1}+a_{12} y_{2}\right)+a_{12}\left(1-a_{11}\right) y_{2} \\
0
\end{array}\right]
$$

and, moving back to the vector of final demands: 


$$
\begin{aligned}
y & =x-A x \\
& =\frac{1}{1-a_{11}}\left[\begin{array}{c}
-a_{11} y_{1}+a_{12} a_{11} y_{2}-a_{12} y_{2}-a_{12} a_{11} y_{2}+y_{1}+a_{12} y_{2} \\
\left(1-a_{11}\right) y_{2}
\end{array}\right] \\
& =\frac{1}{1-a_{11}}\left[\begin{array}{c}
\left(1-a_{11}\right) y_{1} \\
\left(1-a_{11}\right) y_{2}
\end{array}\right]=\left[\begin{array}{l}
y_{1} \\
y_{2}
\end{array}\right]
\end{aligned}
$$

consistently with the calculation of the vector $x$. A similar exercise can be performed exploring the relationship between profits and prices.

In summary, we have added to Quesnay's Tableau Économique a set of structural propositions concerning questions of reproducibility and profitability at different scales of production and for different prices. (Although, of course, not all sectoral price and activity levels lead to profitable or productive situations.) Leontief's IO theory thus leads us from an ex post determination of IO tables for entire economies to interesting, though still basic, propositions of IO analysis as a foundation for questions of income distribution (via cost and price determination) and growth (as determined by investment and quantity formation).

\subsubsection{Connectedness and decomposability of input-output structures}

Before turning to questions of distribution and growth, some helpful definitions and propositions are introduced below. The aim is to clarify the Sraffian concept of basic and nonbasic commodities, and some useful concepts of sectoral interdependencies. In an $n$-good economy a commodity is basic if it enters directly or indirectly the production of all $n$ commodities, as intermediate good, or as intermediate good for intermediate good, and so on. In the matrices above, for example in Table 1.4, there is one basic (good 1) and one nonbasic commodity (good 2). Following Nikaido (1968), the concept of a basic commodity and the related notions of decomposable and primitive matrices can be formally defined: ${ }^{8}$

Definition 1.2. Let $A=\left(a_{i j}\right)$ be the IO matrix of intermediate inputs per unit of output of a closed economy.

(1) We define the $i$-th sector of $A$ (as a supplier) to be directly or indirectly connected to the $j$-th sector and denote this by $i \rightarrow j$, if there exists a chain of intermediate sectors $k_{1}, \ldots, k_{m}$ with $\left(k_{0}=i, k_{m+1}=j\right)$ such that all neighboring sectors of the chain

\footnotetext{
${ }^{8}$ For a detailed analysis of primitive matrices see also Seneta (1973).
} 
exhibit a direct delivery relationship, in the sense that $a_{k_{s}, k_{s+1}}>0$ for all $s \in\{0, \ldots, m\}$.

(2) A commodity $i$ is called a basic commodity, if $i \rightarrow j$ for all $j \in$ $\{1, \ldots, n\}$.

(3) The matrix $A$ is called decomposable, if there exists a proper nonempty subset $J$ of $\{1, \overline{\ldots, n\} \text { such that }}$

$$
a_{i j}=0, \quad i \notin J, j \in J .
$$

(4) The matrix $A$ is called indecomposable, if it is not decomposable.

(5) The indecomposable matrix $A$ is called primitive, if there exists a positive integer $k$ such that $A^{k}>0$ (in the opposite case the matrix is called imprimitive).

Definition 1.2(1) implies that increases in the final demand for good $j$ must eventually lead to increases in the demand for good $i$, and if the IO matrix $A$ is decomposable, then the $n$ produced commodities can be renumbered in such a way that the resulting matrix is of the form

$$
\left[\begin{array}{cc}
A_{11} & A_{12} \\
0 & A_{22}
\end{array}\right]
$$

where the matrix $A_{11}$ represents the interrelationships between the commodities of the set $J, A_{22}$ represents those of the entries $\{1, \ldots, n\}-$ $J$, and $A_{12}$ represents the intermediate inputs from the $J$ sectors to $\{1, \ldots, n\}-J$ subsectors, while $A_{21}=0$, i.e. the $\{1, \ldots, n\}-J$ subsectors do not deliver anything to the $J$ sectors. The latter are therefore independent from the former; however, the commodities produced by sectors $J$ are not necessarily basic commodities while those of subsector $\{1, \ldots, n\}-J$ are nonbasic commodities. If $A_{12}=0$ then both subsystems $J$ and $\{1, \ldots, n\}-J$ are independent of each other and there are no basic commodities. Finally, if the subsystem $A_{11}$ is indecomposable, we have reached the lowest level of decomposability, a situation which we will call a Sraffa matrix. ${ }^{9}$

Before presenting Proposition 1.3 it is helpful to define a cyclical subdivision for an IO matrix. A cyclical subdivision in $r$ subsectors

$$
s_{i} \subset\{1, \ldots, n\}, \quad \bigcup_{i=1}^{i=r} s_{i}=\{1, \ldots, n\}, \quad s_{i} \cap s_{j}=\emptyset, \quad i \neq j, \quad s_{i} \neq \emptyset,
$$

${ }^{9}$ See Nikaido (1968, II.7-8) and Seneta (1973, Ch.1) for an expanded discussion of the principles underlying Proposition 1.3. 
for some IO matrices $A_{s_{i}, s_{i+1}} \geq 0$ implies a matrix with the following structure:

$$
\left[\begin{array}{ccccc}
0 & A_{s_{1}, s_{2}} & 0 & \cdots & 0 \\
0 & 0 & A_{s_{2}, s_{3}} & \cdots & 0 \\
\cdots & \ldots & \cdots & \cdots & \ldots \\
0 & 0 & 0 \ldots & \ldots & A_{s_{r-1}, s_{r}} \\
A_{s_{r}, s_{1}} & 0 & 0 & \ldots & 0
\end{array}\right] .
$$

\section{Proposition 1.3.}

(1) A productive IO matrix $A$ is indecomposable if and only if its Leontief-inverse

$$
(I-A)^{-1}=I+A+A^{2}+A^{3}+\ldots
$$

is strictly positive. This holds if and only if all commodities are basic.

(2) An indecomposable IO matrix $A$ is primitive if and only if there exists no proper and disjoint cyclical subdivision in $r$ subsectors

$$
s_{i} \subset\{1, \ldots, n\}, \quad \bigcup_{i=1}^{i=r} s_{i}=\{1, \ldots, n\}, \quad s_{i} \cap s_{j}=\emptyset, \quad i \neq j, \quad s_{i} \neq \emptyset,
$$

with corresponding $I O$ matrices $A_{s_{i}, s_{i+1}} \geq 0$.

(3) Let $A$ be a productive matrix, $i$ is basic if the $i$-th row of the Leontiefinverse is strictly positive.

(4) Let $A$ be a decomposable matrix of type (1.1). The set of commodities $J$ corresponds to the set of basic commodities if there is at least one basic commodity in the considered subsystem and the matrix $A_{11}$ is indecomposable.

Proposition 1.3 indicates that it may be of great interest to order the given set of commodities to uncover the hierarchies hidden in the coefficients of their IO relationships. First the basic commodities, then the basic commodities of order two (concerning only the remaining sectors), and so on, given their cyclical structure (see Proposition 1.3(2)), imprimitive matrices should play no role in such a restructuring of an IO matrix from the empirical point of view, due to the implausible decoupling of the last level of production to the very first one (from where production starts again in a strictly hierarchical manner). The importance of Proposition 1.3 can be made more clear by providing 
a sense of its proof in Lemma 1.1. The next Lemma provides some methods to check these properties.

Lemma 1.1. Let $A$ be an IO matrix and let $a_{i j}^{(k)}$ represent the entry $A_{i j}^{k}$ of $A$. Then:

(1) $a_{i j}^{(k+l)}=\sum_{\eta=1}^{n} a_{i, \eta}^{(k)} a_{\eta, j}^{(l)}$

(2) There exists a positive integer $k$ such that $a_{i j}^{(k)}>0$ if and only if $i \rightarrow j$.

(3) The matrix $A$ is indecomposable for all sectors represented by $i$ and $j$ if and only if there exists a positive integer $k$ such that $a_{i j}^{(k)}>0$ holds.

(4) A commodity $i$ is basic if and only if for all sectors $j$ there exists a positive integer $k$ such that $a_{i j}^{(k)}>0$ holds.

Observe that in general the choice of $k$ in part (4) depends on the choice of $j$ except for primitive IO matrices where $k$ can be chosen independently of $j$.

The simplest example of an indecomposable matrix $A$ which is imprimitive is given by

$$
A=\left[\begin{array}{cc}
0 & 0.5 \\
0.5 & 0
\end{array}\right]=0.5\left[\begin{array}{ll}
0 & 1 \\
1 & 0
\end{array}\right]
$$

For this matrix there holds

$$
\begin{gathered}
A^{2}=\left[\begin{array}{cc}
0 & 0.5 \\
0.5 & 0
\end{array}\right]\left[\begin{array}{cc}
0 & 0.5 \\
0.5 & 0
\end{array}\right]=0.25\left[\begin{array}{ll}
1 & 0 \\
0 & 1
\end{array}\right], \\
A^{3}=\left[\begin{array}{cc}
0 & 0.5 \\
0.5 & 0
\end{array}\right]\left[\begin{array}{cc}
0 & 0.5 \\
0.5 & 0
\end{array}\right]\left[\begin{array}{cc}
0 & 0.5 \\
0.5 & 0
\end{array}\right]=0.125\left[\begin{array}{ll}
0 & 1 \\
1 & 0
\end{array}\right], \text { etc. }
\end{gathered}
$$

In this example there is a permanent switch between a main-diagonal and an off-diagonal situation, which prevents any matrix $A^{k}$ from becoming strictly positive. The same also holds for matrices of the form:

$$
0.5\left[\begin{array}{lll}
0 & 1 & 0 \\
0 & 0 & 1 \\
1 & 0 & 0
\end{array}\right],
$$

and so on. From the economic point of view these matrices imply that commodity $i$ with $i=1, \ldots, n-1$ is only used by sector $i+1$, for example 
we have a clear hierarchical structure between the considered sectors. However, the last commodity in this hierarchy, commodity $n$, is used by sector 1 and only there, a situation we may find in biological food chains or at the level of firms, but not at the level of entire economies. ${ }^{10}$

In the following, we assume that by suitable renumbering of commodities the matrix structure in equation (1.1) can be obtained where the $s \times s$ matrix $A_{11}$ is primitive; the first $s$ are basic commodities (and thus the $s \times(n-s)$ matrix $A_{12}$ is semi-positive in a specific way); and the $(n-s) \times(n-s)$ matrix $A_{22}$ is just semi-positive. This allows us to focus on the production structure $A_{11}$, since nonbasic commodities are largely irrelevant for the analysis of price and quantity formation, as shown in the next chapter.

Before considering empirical IO tables, it is helpful to quickly sketch out some examples of two-commodity matrices.

1. No means of production: Smith's "early and rude state" of society:

$$
A=\left[\begin{array}{ll}
0 & 0 \\
0 & 0
\end{array}\right]
$$

2. Good 1 used for producing good 2, but not vice versa, i.e. Quesnay to Sraffa matrices:

$$
A=\left[\begin{array}{cc}
0 & a_{12} \\
0 & 0
\end{array}\right], \quad A=\left[\begin{array}{cc}
a_{11} & a_{12} \\
0 & 0
\end{array}\right], \quad A=\left[\begin{array}{cc}
a_{11} & a_{12} \\
0 & a_{22}
\end{array}\right]
$$

3. Indecomposable and primitive (not cyclical, Leontief matrices):

$$
A=\left[\begin{array}{ll}
a_{11} & a_{12} \\
a_{21} & a_{22}
\end{array}\right]
$$

4. Indecomposable, but not primitive (circular production structures):

$$
A=\left[\begin{array}{cc}
0 & a_{12} \\
a_{21} & 0
\end{array}\right] \text {. }
$$

5. Completely decomposable (basic two country situation):

${ }^{10}$ Further discussion on helpful rearrangements of rows and columns of matrices can be found in the Appendix to this chapter. 


$$
A=\left[\begin{array}{cc}
a_{11} & 0 \\
0 & a_{22}
\end{array}\right] \text {. }
$$

Even in the case of only two commodities, we find a number of qualitatively different production structures which can be classified focusing on good 1. ${ }^{11}$ The seven matrices can be called, respectively, Smith-matrices, Austrian-matrices, Quesnay-matrices, Sraffa-matrices, von-Neumann-matrices, (biological) hypercycle-matrices, and twocountry-matrices.

\subsection{Contemporary empirical input-output tables}

\subsubsection{Input-output tables in open economies}

In the rest of the book, we will assume that the IO matrices $A \in \mathbb{R}_{+}^{n \times n}$ are productive. Then, the basic input-output equation for an economy,

$$
x=A x+y,
$$

is well-defined for any given vector of final demands $y \in \mathbb{R}_{+}^{n}$.

In Section 1.2 the matrix coefficients $a_{i j}$ were defined to represent the quantity of good $i$ used up in the production of one unit of good $j$. This characterization involves an implicit assumption. Since the vector $x$ on the left-hand side of equation (1.2) refers to production in a given country, say, the home country, a sector $j$ obtains the quantity $a_{i j} x_{j}$ on the right-hand side of equation (1.2) exclusively from the domestic sector $i$. If $a_{i j}$ is the quantity of good $i$ that is technologically required per unit of output $j$, sector $j$ buys all it needs on the domestic market, and the same is true for all sectors. Therefore, equation (1.2) refers to a closed economy, or at least to an economy that imports no intermediate goods.

The assumption of a closed economy may have been reasonable at the time Quesnay designed his Tableau Économique, but it is certainly obsolete today. Hence we must distinguish between what is technologically needed, and what is bought in the home country and abroad, respectively. To this effect, let $A_{T}, H$, and $A$ be $n \times n$ matrices with respective elements $a_{T ; i j}, h_{i j}$, and $a_{i j}$. The coefficient $a_{T ; i j}$ represents the quantity of good $i$ that is technologically required to produce one unit of output $j, h_{i j}$ is the share of input good $i$ that sector $j$ buys in the home country (the home share), and $a_{i j}$ is the

$\overline{11}$ There are corresponding further cases if one looks at these structures focusing on good 2 . 
quantity of input $i$ per unit of output that sector $j$ buys on the domestic market. The coefficients specified above are related through equation (1.3):

$$
\underset{\text { domestic coefficient }}{a_{i j}}=\underset{\text { home share }}{h_{i j}} \cdot a_{T, i j} \cdot \text { tech. coefficient }_{\text {hom }}
$$

With the above interpretation of the matrix $A$, equation (1.2) continues to apply as the basic IO equation for open economies.

Monetary relations must also be modified accordingly. Let $\nu_{j}$ be the value added per unit of output $j$, which for the time being may be thought to be exogenously given. For the sake of notational simplicity suppose that there are no price differentials at home and abroad. The price equation for sector $j$ would read $p_{j}=\sum_{i} a_{T ; i j} p_{i}+\nu_{j}$ or, in vector form:

$$
p=p A_{T}+\nu \text {. }
$$

In closed economies, where $A=A_{T}$, equations (1.2) and (1.4) constitute a nice dual representation of the economy, but the direct correspondence is lost in open economies.

\subsubsection{Aggregation of input-output tables}

In theory, we can conceive of an economy producing $n$ goods and refer to the quantities of all these goods. Yet there are thousands of goods on the market. In the real world even the most detailed statistics cannot record each and every good, and even at the most elementary level several goods are combined into aggregate goods. Thus in applied work the expression "quantity of good $i$ " must not be taken literally. Rather, it means something like: "One unit of good $i$ is a bundle of (physically different) goods that are assigned to a category $i$. Valued at prices of a given base year, it is worth one million Euros." 12

It is important to note that the prices in the base year $p^{b}$ are all unity: $p_{i}^{b}=1$ for all $i$. Hence, we may add up the column coefficients of a real IO table: $\sum_{i} a_{i j}$ should then be interpreted as $\sum_{i} p_{i}^{b} a_{i j}$, which reflects the value of the intermediate inputs in terms of the base year prices per unit of output $j$. However, with respect to some other price vector $p \neq p^{b}$ a term like $p_{i} x_{i}$ would mean the value of a bundle of goods assigned to category $i$, which if valued at the base year prices, would be worth $x_{i}$ million Euros. Under this proviso, we can refer to $p_{i} x_{i}$ as the value of (the quantity of) $x_{i}$ units of good $i$.

12 One million Euros in prices of the year 1995 is the monetary unit underlying the real (as opposed to the nominal) IO tables for Germany over the decade 1991-2000. It does not matter whether it is a million Euros or another sum of money, this is just a matter of scale. 
This brief sketch of how to interpret the "quantities" of goods is the basis of all aggregation procedures for IO tables. In preparing IO tables for national economies, statistical offices necessarily perform a great deal of aggregation. For example, the IO tables of Germany distinguish 71 categories of goods, produced in 71 sectors. This is a relatively high degree of differentiation that is useful for a variety of applications. In order to study the sectoral interrelationships and their implications, however, $71 \times 71$ tables are often quite unwieldy and it may be appropriate to aggregate these data further.

The basic tool in aggregating IO matrices is a so-called binary "summation matrix" $\mathcal{S}$. In order to illustrate the general procedure, consider first a simple three-good economy where the first two goods are to be aggregated into one composite good. Consider again the matrix $X$ of intersectoral flows

$$
X=\left[\begin{array}{lll}
a & b & c \\
d & e & f \\
g & h & i
\end{array}\right] .
$$

Let $X^{\star}$ be the aggregated version of $X$, where $x_{11}^{\star}$ is the sum of all flows between the two original sectors 1 and $2 ; x_{21}^{\star}$ sums up the flows of the original sectors 1 and 2 to the original sector 3 , which is now counted as sector 2 ; etc. Thus we get

$$
X^{\star}=\left[\begin{array}{cc}
a+b+d+e & c+f \\
g+h & i
\end{array}\right] .
$$

The summation matrix $\mathcal{S}$ describes the transition from $X$ to $X^{\star}$ in a compact way. It is a matrix of order $2 \times 3$, specified as

$$
\mathcal{S}=\left[\begin{array}{lll}
1 & 1 & 0 \\
0 & 0 & 1
\end{array}\right] \text {. }
$$

It is then easily checked that

$$
X^{\star}=S X \mathcal{S}^{\prime}
$$

Equation (1.5) remains valid even if, where there are $1, \ldots, n$ original sectors that are aggregated to $1, \ldots, M$, macro sectors. To be specific, let $J_{m}$ be the index set of the original sectors that are assigned to macro sector $m\left(m=1, \ldots, M\right.$; so, $J_{1}=\{1,2\}$ and $J_{2}=\{3\}$ in our example). 
In this case, $\mathcal{S}$ is of order $M \times n$, and its entries are given by

$$
s_{m j}= \begin{cases}1 & \text { if the original sector } j \in J_{m} \\ 0 & \text { otherwise. }\end{cases}
$$

Besides (1.5), matrix $\mathcal{S}$ is also used to describe how to move from an original activity vector $x \in \mathbb{R}_{+}^{n}$ to the aggregated vector $x^{\star} \in \mathbb{R}_{+}^{M}$ with components $x_{m}^{\star}=\sum_{j \in J_{m}} x_{j}$ :

$$
x^{\star}=\mathcal{S} x,
$$

and likewise for the final demand vectors $y$ and $y^{\star}$, or any other quantity vectors.

Things are a bit more involved when we turn from the total flows in $X$ and $X^{\star}$ to the coefficient matrix $A \in \mathbb{R}_{+}^{n \times n}$ and its aggregated counterpart $A^{\star} \in \mathbb{R}_{+}^{M \times M}$. To explore these complications, let $\widehat{x}$ denote the $n \times n$ diagonal matrix where entries $x_{j}$ on the main diagonal are the elements of the production vector $x \in \mathbb{R}_{+}^{n}$; likewise for $\widehat{x}^{\star} \in \mathbb{R}_{+}^{M}$. The transition from $A$ to $A^{\star}$ is summarized by Proposition 1.4.

Proposition 1.4. Let $A \in \mathbb{R}_{+}^{n \times n}$ be an IO matrix and $x \in \mathbb{R}_{++}^{n}$ a strictly positive activity vector that is associated with it. Let the aggregation of the $n$-sectoral economy into an $M$-sectoral economy be described by the matrix $\mathcal{S}$ in equation (1.6). Let $x^{\star}=\mathcal{S} x$, then the aggregated IO matrix $A^{\star} \in \mathbb{R}_{+}^{M \times M}$ can be obtained from $A$ and $x$ as follows

$$
A^{\star}=\mathcal{S} A \widehat{x} \mathcal{S}^{\prime}\left(\widehat{x}^{\star}\right)^{-1}
$$

Proof. By definition, for all $i, j, a_{i j}=X_{i j} / x_{j}$. Therefore, in matrix form $A \widehat{x}=X$. By the same token, $A^{\star} \widehat{x}^{\star}=X^{\star}$. Thus, $A^{\star} \widehat{x}^{\star}=X^{\star}=$ $\mathcal{S} X \mathcal{S}^{\prime}=\mathcal{S} A \widehat{x} \mathcal{S}^{\prime}$, where the second equality follows from (1.5). The result follows by post-multiplying the outer terms in this chain by the inverse of $\widehat{x}^{\star}$.

The relationship applies whether $A$ is the matrix of domestic coefficients or (with $A=A_{T}$ ) of technological coefficients. It should be noted that this aggregation procedure is based on a given output vector containing the empirical sectoral outputs.

\subsubsection{Examples of aggregated input-output tables}

Going back to Quesnay, Table 1.4 provides an early example of a $2 \times 2 \mathrm{IO}$ table. It has, however, two unrealistic features: the coefficients appear 
too small (as reflected in the high associated profit rates), and the matrix is not only decomposable, but one of the two goods does not enter production at all. With a basic understanding of the notion of aggregation, we can now set up a more relevant numerical example. It is constructed from the German IO tables (in real terms), where the original 71 production sectors are aggregated up to two (macro) sectors: the industry sector and the services sector. This constitutes our twosectoral standard aggregation. The relative size of the two sectors is illustrated in Table 1.9, which displays the sectoral output shares for Germany in the year 2000. This will serve as our empirical reference point throughout the book. ${ }^{13}$

1: The industry sector $42.5 \%$

2: The services sector $57.5 \%$

Table 1.9: The two-sectoral standard aggregation

For the same country and year, the matrices $A_{T}$ and $A$ in equation (1.8) present the technological and the domestic IO coefficients computed from the original $71 \times 71$ tables, using the procedure outlined in Proposition 1.4. It is evident that the distinction in section 1.4.1 between the technological and domestic coefficients is relevant, especially for the intrasectoral flows in the industry sector. About a third of this composite input good is imported from abroad $(0.432-0.286) / 0.432=0.340$. Similarly, the services sector buys $7.8 \%$ of the services necessary for production on foreign markets.

$$
A_{T}=\left[\begin{array}{ll}
0.432 & 0.073 \\
0.199 & 0.312
\end{array}\right], \quad A=\left[\begin{array}{ll}
0.286 & 0.060 \\
0.191 & 0.287
\end{array}\right]
$$

As should be clear from section 1.4.1, the notion of the Leontief-inverse involves the matrix $A$ of the domestic coefficients. Given equation (1.8), the Leontief-inverse is

13 The "industry sector" comprises agriculture, manufacturing, and construction. The percentage numbers are the sectoral output shares in gross output of Germany in 2000. 


$$
\begin{aligned}
(I-A)^{-1} & =\frac{1}{\left(1-a_{11}\right)\left(1-a_{22}\right)-a_{12} a_{21}}\left[\begin{array}{cc}
1-a_{22} & a_{12} \\
a_{21} & 1-a_{11}
\end{array}\right] \\
& =\left[\begin{array}{ll}
1.432 & 0.121 \\
0.383 & 1.436
\end{array}\right] .
\end{aligned}
$$

According to equation (1.9), an increase in the final demand for the industrial good by one million Euros in 1995 prices raises the output of this sector by 1.432 million Euros. The resulting increase in services to provide the production processes with the necessary inputs is 0.383 million Euro. Thus a one million increase in final demand raises total economic activity by 1.815 million Euros. Foreign countries profit too, but in this basic framework we are ignoring this possible effect and any possible feedback effects on the home country.

The impact of an increase in the final demand for services on total economic activity is less pronounced. Here, the "multiplier" is only 1.556 (the difference from $0.121+1.436=1.557$ is due to rounding errors).

A two-sector aggregation may be convenient to illustrate some basic features - in other respects it is, of course, very crude. For a more detailed picture of the economy, we occasionally work with a 7-sector aggregation. The industry sector is split up into agriculture, manufacturing, and construction. Within manufacturing itself, we separate out another subsector which for an export-oriented country like Germany should be of particular importance. It comprises the four single production sectors (among the 71 original sectors) with the highest exports: chemicals, pharmaceuticals, machinery, and motor vehicles. We call this macro sector the export core. ${ }^{14}$

The services sector produces very different output 'goods'. We distinguish between three of them: business-related services, consumer services, and social services. The term business-related services needs further clarification. For one of the 71 original sectors of the German IO tables is labeled thus, and has grown considerably over the 1990s with an output share that in 2000 rose to almost seven percent (it is thus larger than the construction sector). This single sector may be viewed as business-related services in a narrow sense. For our aggregation, however, we understand this term in a broader sense and include the

${ }^{14}$ The specification of this export core has proved fruitful in the investigation of the impact that the structural change in the industrial sector has on the other sectors; see Kalmbach, Franke, Knottenbauer, and Krämer (2005). 
following sectors: wholesale trade, communications, finance, leasing, computer and related services, research and development services. In contrast consumer services comprise: retail trade, repair, transport, insurance, real estate services, and personal services. ${ }^{15}$

Table 1.10 summarizes the seven (macro) sectors obtained. For a better assessment of their relative importance, it also indicates the sectoral output shares (in the year 2000). According to this criterion, agriculture could have well been included in what we have called other manufacturing (which would be sensible given the industrial character of today's agriculture and fisheries). We consider it separately for conventional reasons. The technological coefficients of the 7 -sectoral aggregation are reported in Table 1.11.

\begin{tabular}{|lr|}
\hline (1): Agriculture (Agrc.) & 1.33 \\
(2): Manufacturing, the export & 12.37 \\
& core (Manf.) \\
(3): Other manufacturing & 22.55 \\
$\quad$ (Oth.Mf.) & \\
(4): Construction (Cstrt.) & 6.29 \\
(5): Business-related services & 21.36 \\
$\quad$ (Bus.Svcs.) & \\
(6): Consumer services & 23.35 \\
$\quad$ (Cns.Svcs.) & \\
(7): Social services (Soc.Svcs.) & 12.75 \\
\hline
\end{tabular}

Table 1.10: The 7-sector standard aggregation

Note: The numbers in the last column are the sectoral output shares (in percent) for Germany in 2000.

$\overline{15}$ Business-related services do not exclusively work for enterprises and consumer services do not exclusively serve the consumer. Our distinction between the two is justified by the relatively high share of $68.9 \%$ of the output of business-related services that is purchased as intermediate inputs by the other sectors (and themselves, in 2000). This is almost 30 percentage points above the average share of $40.2 \%$ of total output in the economy. By contrast, the consumer services' share of output used as intermediate inputs is as low as $32.3 \%$. The shares of real estate services and insurance (without social insurance), which are assigned to the consumer services, are actually not much higher: they amount to $35.2 \%$ and $33.5 \%$, respectively. 

(1)
(2)
(3)
(4)
(5)
(6)

(7)

Agrc. Manf. Oth.Mf. Cstrt. Bus.Svcs. Cns.Svcs. Soc.Svcs.

\begin{tabular}{|c|c|c|c|c|c|c|c|}
\hline Agrc. & 0.028 & 0.000 & 0.045 & 0.000 & 0.000 & 0.002 & 0.002 \\
\hline Ianf. & 0.090 & 0.282 & 0.050 & 0.022 & 0.003 & 0.008 & 0.011 \\
\hline Oth.Mf. & 0.142 & 0.232 & 0.324 & 0.287 & 0.030 & 0.055 & 0.065 \\
\hline Cstrt. & 0.007 & 0.003 & 0.006 & 0.017 & 0.006 & 0.028 & 0.016 \\
\hline Bus.Sv & 0.142 & 0.121 & 0.140 & 0.107 & 0.332 & 0.134 & 0.096 \\
\hline Cns.Sve & 0.036 & 0.053 & 0.051 & 0.108 & 0.072 & 0.152 & 0.049 \\
\hline oc.Svcs & 0.031 & 0.006 & 0.011 & 0.007 & 0.007 & 0.013 & 0.02 \\
\hline
\end{tabular}

Table 1.11: Technological coefficients of the 7-sector aggregation (Germany, 2000)

Regarding the domestic coefficients for the 7-sector aggregation, it is more insightful to directly report the import shares for the different intermediate goods (referring to (1.3), these shares are given by $1-h_{i j}$ ). This is done in Table 1.12.
(1)
(2)
(3)
(4)
(5)
(6)
(7)

Agrc. Manf. Oth.Mf. Cstrt. Bus.Svcs. Cns.Svcs. Soc.Svcs.

\begin{tabular}{lccccccc}
\hline Agrc. & 12.2 & 57.4 & 26.1 & 0.0 & 0.0 & 22.2 & 21.3 \\
Manf. & 56.4 & 38.4 & 46.1 & 28.1 & 69.0 & 21.7 & 47.7 \\
Oth.Mf. & 16.4 & 30.2 & 37.8 & 16.1 & 19.2 & 21.1 & 24.4 \\
Cstrt. & 0.3 & 0.4 & 8.8 & 41.6 & 0.3 & 0.4 & 0.2 \\
Bus.Svcs. & 0.1 & 5.3 & 1.9 & 0.5 & 9.6 & 2.9 & 4.4 \\
Cns.Svcs & 7.5 & 8.6 & 7.4 & 6.3 & 7.8 & 9.9 & 4.9 \\
Soc.Svcs. & 0.0 & 11.6 & 2.0 & 0.0 & 12.2 & 0.0 & 17.2 \\
\hline
\end{tabular}

Table 1.12: Import shares (in percent) for the 7-sector aggregation

Tables 1.11 and 1.12 provide all the information needed to compute the Leontief-inverse for the 7-sector economy; first compute matrix $A$ of the domestic coefficients, and subsequently invert matrix $I-A$. The Leontief-inverse is shown in Table 1.13. The last row of the table 
computes the column sums. Just as in the two-sector example discussed above, they give the increase in total economic activity induced by a unit increase of final demand for the respective good, and they may be interpreted as economy-wide multipliers.

Regarding the impact on the output of the different sectors, we point out that if we discount for the direct effects (i.e. if unity is subtracted from the diagonal elements), then it is the business-related services that profit the most from increases in final demand (except for an increase in demand for construction). ${ }^{16}$ In short, the fifth row dominates the other rows. This could not be easily predicted from Table 1.11, where the entries of the fifth row are not clearly dominant. ${ }^{17}$ The dominant output gains of the business-related services are one example of intersectoral IO relationships leading to results that are not a priori obvious.
(1)
(2)
(3)
(4)
(5)
(6)

Agrc. Manf. Oth.Mf. Cstrt. Bus.Svcs. Cns.Svcs. Soc.Svcs.

\begin{tabular}{llllllll}
\hline Agrc. & 1.032 & 0.010 & 0.044 & 0.012 & 0.002 & 0.005 & 0.005 \\
Manf. & 0.056 & 1.220 & 0.046 & 0.033 & 0.005 & 0.014 & 0.011 \\
Oth.Mf. & 0.184 & 0.268 & 1.287 & 0.332 & 0.057 & 0.088 & 0.081 \\
Cstrt. & 0.013 & 0.011 & 0.012 & 1.019 & 0.013 & 0.036 & 0.020 \\
Bus.Srcs. & 0.276 & 0.278 & 0.292 & 0.260 & 1.468 & 0.249 & 0.170 \\
Cns.Svcs. & 0.077 & 0.107 & 0.100 & 0.160 & 0.118 & 1.188 & 0.076 \\
Soc.Srvcs. 0.038 & 0.014 & 0.019 & 0.015 & 0.012 & 0.019 & 1.024 \\
\hline & & & & & & & \\
$\sum$ : & 1.676 & 1.907 & 1.800 & 1.830 & 1.674 & 1.599 & 1.387 \\
\hline
\end{tabular}

Table 1.13: The Leontief-inverse $(I-A)^{-1}$ for the 7-sector aggregation (Germany, 2000)

\subsection{Conclusions}

This chapter has analyzed Quesnay's Tableau Économique in order to introduce some fundamental concepts of IO theory. We have started from simple, small-scale examples similar to those used by

${ }^{16}$ Observe that the numbers in the entries $i, j$ of Table 1.13 can be directly compared, the common unit being "bundles of goods of category $i$ worth one million Euros in prices of 1995".

17 This characterization also holds for the matrix $A$. 
Quesnay himself and quickly advanced to full-scale examples of modern economies with extensive division of labor. The properties of IO matrices that are of primary concern reflect, on the one hand, their potential to generate physical and economic surpluses across sectors, and on the other hand, the degree of connectedness of an $n$-sector economy.

The IO tools introduced in this chapter allow us to provide a complete description of the flows of goods and services in the economy, capturing the physical interconnections between sectors, and a snapshot of the technological knowledge and productive structure of the economy. However, they also provide the foundations for the analysis of the classical notions of production prices and balanced growth pathsintroduced by classical authors like Smith, Ricardo, and Marx - that will be considered in the rest of the book. Certainly, the structure of advanced capitalist economies is far more complicated than the matrices of intermediate inputs considered in this chapter (which, for example, exclude the existence of joint products and fixed capital). We shall consider these complications in the rest of the book by gradually relaxing some of the simplifying assumptions of the basic IO model.

As a first step, while this chapter examined IO structures in which labor is considered part of the means of production (by implicitly assuming a given subsistence wage), the next chapter examines concepts directly relevant to labor - such as labor values, the rate of exploitation, and changes in real wages - more explicitly.

\subsection{Appendix: Further properties of matrices}

\subsubsection{Dominant diagonal matrices}

A matrix $M=I-A$ has a dominant diagonal if

$$
\left|m_{i i}\right|>\sum_{i \neq j}\left|m_{i j}\right| \text { for all } i=1, \ldots, n \text {. }
$$

It has a dominant diagonal in the extended sense if and only if there exist real numbers $d_{j}>0 \quad(j=1, \ldots, n)$ such that:

$$
d_{i}\left|m_{i i}\right|>\sum_{i \neq j} d_{j}\left|m_{i j}\right| \quad \text { for all } \quad i=1, \ldots, n .
$$

Finally the matrix $M$ has a positive dominant diagonal if and only if there exist $d_{i}>0, i=1, \ldots, n$, such that 


$$
d_{i}\left|m_{i i}\right|>\sum_{i \neq j} d_{j}\left|m_{i j}\right|, \quad \text { and } \quad m_{i i}>0 \text { for } i=1, \ldots, n .
$$

The latter two criteria are sufficient to imply the Hawkins-Simon conditions and thus all four statements in Proposition 1.2. In terms of the difference matrix $M$ this means that each sector produces more of its own product than it consumes and (as the first condition) that this surplus dominates the coefficients $\left|m_{i j}\right|=-a_{i j}$ that describe the consumption of good $i$ by the other sectors of the economy (when combined with appropriate weights).

If applied to the matrix $M=I-A$, where $A$ is nonnegative, a dominant diagonal is equivalent to the productivity of $A$. In fact, if $A$ is productive there exists a vector $\breve{x} \geq 0$ with $\breve{x}>A \breve{x}$. If $\breve{x}$ contains some zero components, a slight perturbation of $\breve{x}$ yields a strictly positive vector $x$ with this property. Thus, we have $M x>0$ or

$$
m_{i i} x_{i}+\sum_{i \neq j} m_{i j} x_{j}>0 \text { for all } i
$$

Since $m_{i j}<0$ for $j \neq i$, the latter inequality can be rewritten as

$$
\left|m_{i i}\right| x_{i}>\sum_{i \neq j}\left|m_{i j}\right| x_{j} \quad \text { for all } i
$$

So it only remains to replace $x_{j}$ by $d_{j}$. The converse statement follows from similar considerations.

If instead of row sums, the definition of dominant diagonal were in terms of column sums, then dominant diagonal applied to $M=I-A$ would be equivalent to the profitability of the matrix $A$.

1.6.2 Useful manipulations of rows and columns of matrices

The rows and columns of the matrix

$$
A=\left[\begin{array}{llll}
2 & 0 & 1 & 1 \\
0 & 6 & 0 & 5 \\
3 & 1 & 4 & 0 \\
0 & 7 & 0 & 8
\end{array}\right]
$$

can be rearranged so as to get the following input structure 


$$
A=\left[\begin{array}{llll}
2 & 1 & 0 & 1 \\
3 & 4 & 1 & 0 \\
0 & 0 & 6 & 5 \\
0 & 0 & 7 & 8
\end{array}\right] .
$$

Therefore this IO matrix exhibits two basic and two nonbasic commodities or industries.

Strictly hierarchically structured production technologies are given by matrices that can be triangularized as follows:

$$
\left[\begin{array}{ccccc}
a_{11} & a_{12} & a_{13} & \ldots & a_{1 n} \\
0 & a_{22} & a_{23} & \ldots & a_{2 n} \\
0 & 0 & a_{33} & \ldots & a_{3 n} \\
\ldots & \ldots & \ldots & \ldots & \ldots \\
0 & 0 & 0 \ldots & \ldots & a_{n-1, n} \\
0 & 0 & 0 \ldots & \ldots & a_{n n}
\end{array}\right], \quad\left[\begin{array}{ccccc}
0 & a_{12} & a_{13} & \ldots & a_{1 n} \\
0 & 0 & a_{23} & \ldots & a_{2 n} \\
\ldots & \ldots & \ldots & \ldots & \ldots \\
0 & 0 & 0 \ldots & \ldots & a_{n-1, n} \\
0 & 0 & 0 \ldots & \ldots & 0
\end{array}\right]
$$

possibly with further decomposable structures within the triangular part. Clearly, the first matrix is indecomposable and primitive, while the second is decomposable and with no basic commodity. 